\title{
Merokok dan Penuaan Dini berupa Wrinkles Seputar Wajah Sekuriti Universitas Islam Bandung
}

\author{
Deis Hikmawati, ${ }^{1}$ Diany Maedasari, ${ }^{2}$ Panji Ramdhani Prasetya ${ }^{2}$ \\ ${ }^{1}$ Bagian Ilmu Kesehatan Kulit dan Kelamin, ${ }^{2}$ Fakultas Kedokteran, Universitas Islam Bandung, Bandung
}

\begin{abstract}
Abstrak
Penuaan dini (PD) adalah proses degeneratif yang melibatkan kulit dan sistem penyokong kulit meliputi tulang, kartilago dan jaringan subkutaneus, berupa perubahan stuktural dan elastilitas kulit yang ditandai dengan wrinkles/kerutan kulit (fine wrinkles, coarse wrinkles), kulit yang kasar, kulit kering, teleangiaektasi, lesi kanker, serta perubahan pigmentasi. Wrinkles adalah permukaan kulit yang mengalami lekukan, dipengaruhi oleh faktor intrinsik dan ekstrinsik. Faktor ekstrinsik berasal dari lingkungan paparan sinar matahari, polusi udara, rokok, pergerakan otot yang berulang terkait ekspresi wajah, serta kebiasaan gaya hidup yang berhubungan dengan pola makan dan posisi tidur. Tujuan penelitian ini adalah apakah merokok sebagai faktor ekstrinsik berefek pada kejadian penuaan dini berupa wrinkles di seputar wajah, yaitu sekitar mata, nasolabial fold, dan bibir pada sekuriti Universitas Islam Bandung (Unisba) usia 20-40 tahun. Penelitian ini merupakan penelitian deskriptif analitik menggunakan metode potong lintang. Subjek penelitian adalah pegawai Unisba, yaitu sekuriti berusia 20-40 tahun yang memenuhi kriteria inklusi dengan jumlah 68 orang selama periode Maret-Juni 2016. Penelitian ini menggunakan formulir penelitian yang terdiri atas 16 pertanyaan. Uji analisis menggunakan uji chi-square. Hasil penelitian berupa wrinkles di dahi $(\mathrm{p}=0,272)$, seputar mata $(\mathrm{p}=0,203)$, nasolabial fold $(\mathrm{p}=0,493)$, dan bibir $(0,493)$ menunjukkan bahwa tidak terdapat hubungan merokok dengan penuaan dini berupa wrinkles di dahi, seputar mata, nasolabial fold, dan bibir ( $p>0,05$ ). Simpulan, merokok tidak berefek pada penuaan dini berupa wrinkles di dahi, seputar mata, nasolabial fold, dan bibir pada sekuriti Unisba usia 20-40 tahun.
\end{abstract}

Kata kunci: Merokok, penuaan dini, wrinkles

\section{Smoking and Premature Aging in Form of Facial Wrinkles on Universitas Islam Bandung Security Staff}

\begin{abstract}
Premature aging is a degenerative process that involves the skin and the skin support systems including the bone, cartilage, and subcutaneous compartments which is skin structural and elastic change characterized such as wrinkles (fine wrinkles, coarse wrinkles), rough skin, dry skin, teleangiaectasia, cancerous lesions, and changes in pigmentation. Wrinkles are curvature of skin surface. There are two factors influence, namely intrinsic and extrinsic factors. Extrinsic factors associated with exposure to sunlight, air pollution, smoking, repetitive muscle movements, diet and sleep position. The objective of the study was to determine the effects of smoking as external factor in the incidence of premature aging such as wrinkles based on area around the face as forehead, around eyes, nasolabial fold, and lips of 68 Universitas Islam Bandung (Unisba) security staff around 20-40 years old. This study was descriptive analytic using cross sectional method during period March to June 2015. This study used the form in the form consisted of 16 questions. Analyzed test using chi-square method. The result related to wrinkles in forehead was $(\mathrm{p}=0.272)$, around eyes $(\mathrm{p}=0.203)$, nasolabial fold $(\mathrm{p}=0.493)$ and lips $(0.493)$. The result showed that there was no significant relation between smoking and premature aging such as wrinkles on forehead and wrinkles around crows feet, nasolabial fold and lip ( $\mathrm{p}>0.05$ ). In conclusion, smoking has no relation with premature aging such as wrinkles on forehead and wrinkles around the lips, crows feet, nasolabial fold of Unisba security staff aged 20-40 years old.
\end{abstract}

Key words: Premature aging, smoking, wrinkles

Korespondensi: Deis Hikmawati, dr., Sp.KK, MKes. Bagian Ilmu Kesehatan Kulit dan Kelamin, Fakultas Kedokteran, Universitas Islam Bandung. Jln. Tamansari No. 22, Bandung, Jawa Barat, Indonesia. Telepon: +6222 4203368, ext.: 6905. Faksimile: +6222 4231213. HP: +62811231917. E-mail: drdeishh@yahoo.com 


\section{Pendahuluan}

Pada waktu ini salah satu masalah yang sering didapatkan dalam praktik oleh dokter spesialis kulit dan kelamin adalah penuaaan dini (PD). ${ }^{1}$ Setiap manusia akan memiliki masalah tersendiri mengenai wajahnya yang menyenangkan maupun tidak menyenangkan. Terdapat penelitian pada wajah yang berhubungan dengan penuaan dini pada kulit wajah pada beberapa tahun terakhir. ${ }^{2}$

Penuaan dini merupakan proses degeneratif yang melibatkan kulit dan juga sistem penyokong kulit meliputi tulang, kartilago, serta jaringan subkutaneus $^{3}$ berupa perubahan stuktural dan elastilitas kulit yang ditandai dengan wrinkles/ kerutan kulit (fine wrinkles, coarse wrinkles), kulit yang kasar, kulit kering, teleangiaektasi, lesi kanker, serta perubahan pigmentasi. ${ }^{1-3}$ Penuaan dini pada kulit dipengaruhi oleh faktor intrinsik dan ekstrinsik. ${ }^{3,4}$ Kedua faktor itu diawali dengan integritas struktur kulit hilang secara progresif dan fungsi fisiologi kulit. ${ }^{4}$ Faktor ekstrinsik yang berasal dari lingkungan merupakan paparan sinar matahari, polusi udara, rokok, pergerakan otot yang berulang terkait ekspresi wajah mata, serta kebiasaan gaya hidup yang berhubungan dengan pola makan dan juga posisi tidur. Tanda faktor ekstrinsik berupa telangietaksis, perubahan pada pigmentasi, kerusakan kolagen dan elastin, serta dehidrasi kulit dan kulit yang kendur. ${ }^{3,4}$ Wrinkles adalah permukaan kulit yang mengalami lekukan yang disebabkan perubahan struktur epidermis, dermis, dan hipodermis ${ }^{5}$ berupa wrinkles crow's feet di sekeliling mata, garis dahi yang melintang, sekitar bibir, dan lipatan nasolabial. ${ }^{6}$

Nikotin yang terkandung dalam rokok dapat mengakibatkan kerusakan pada kulit dengan cara meningkatkan kadar vasopresin menimbulkan vasokontriksi pada pembuluh darah jaringan kutaneus yang menurunkan suplai aliran darah sehingga oksigen serta nutrisi kulit berkurang. Keadaan tersebut akan mengakibatkan kelainan kulit berupa wrinkles pada kulit. ${ }^{4}$

Pengaruh rokok juga dapat mengakibatkan penuaan dini diakibatkan penurunan kolagen, peningkatan tropoelastin kulit, juga perubahan proteoglikan dan menginduksi matrix metallo proteinase-1 atau MMP-1.7 Hubungan merokok dengan penuaan dini berupa wrinkles bergantung pada jumlah rokok yang dihirup per hari dan lamanya merokok setiap individu. Karakteristik wrinkles pada penuaan dini yang dihubungkan dengan perokok dapat dilihat distribusinya di daerah seputar mata dan wrinkles yang dalam disebut smoker's face. Merokok itu lebih sering menimbulkan wrinkles di daerah periorbital bila dibanding dengan paparan sinar ultraviolet. ${ }^{8}$

Penelitian oleh Muizzuddin dkk. ${ }^{9}$ melaporkan perbandingan antara wrinkles dan merokok yang telah menjadi perokok aktif yang telah merokok satu pak per hari lebih dari 5 tahun dengan yang tidak merokok. ${ }^{9,10}$ Penelitian Freiman dkk. yang dikutip dari penelitian Drakaki dkk. ${ }^{8}$ juga dijelaskan bahwa perokok berat 4,7 kali lebih sering mengalami wrinkles dibandingkan dengan bukan perokok.

Sebuah perguruan tinggi negeri atau swasta pasti memerlukan suatu sistem keamanan yang meliputi beberapa orang sekuriti yang bekerja berkelompok. Berdasar atas observasi banyak sekuriti yang memiliki kebiasaan merokok dan mengeluhkan kerut pada wajah. Tujuan penelitian ini apakah merokok berefek pada penuaan dini berupa wrinkles di seputar wajah pada sekuriti Universitas Islam Bandung (Unisba) berusia 2040 tahun.

\section{Metode}

Metode penelitian ini adalah deskriptif analitik dengan desain potong lintang untuk memperoleh informasi mengenai hubungan perilaku merokok dengan wrinkles pada wajah sekuriti Unisba. Subjek yang digunakan adalah responden yang memenuhi kriteria inklusi, yaitu sekuriti yang merokok dan tidak merokok sebagai kelompok uji dan kontrol berusia 20-40 tahun. Kriteria eksklusi adalah tingkat stres yang tinggi, memiliki penyakit kulit lain, minum alkohol, dan sering terkena paparan sinar ultraviolet.

Besar sampel yang digunakan dalam penelitian ini 68 orang terdiri atas 34 responden merokok dan 34 responden tidak merokok masing-masing. Penelitian ini dilaksanakan Maret sampai Juni 2015 di lingkungan kampus Unisba.

Kepada seluruh subjek penelitian dilakukan pengisian formulir yang berisikan pertanyaan mengenai kerut wajah/wrinkles dan kebiasaan merokok. Setiap foto subjek penelitian ini yang menggambarkan keadaan wrinkles itu diambil oleh peneliti menggunakan kamera digital yang telah distandardisasi sebelumnya terlebih dahulu tanpa mempergunakan flash. Pengambilan foto dalam tiga posisi, yaitu kiri, kanan, dan bagian depan. Seluruh formulir yang telah diisi oleh sekuriti dikumpulkan lalu dilakukan pengecekan 
ulang kecocokan identitas subjek dengan foto.

Analisis data form yang diisi oleh responden kemudian dilakukan penyesuaian foto itu dan diberikan penilaian atau didiagnosis, kemudian dilanjutkan dengan input semua data. Data yang dipergunakan dalam penelitian ini termasuk data kategorik maka hasil ukurnya adalah chi-square untuk mengetahui ada atau tidaknya hubungan merokok dengan wrinkles.

\section{Hasil}

Berdasarkan atas tabel proporsi merokok pada Tabel 1, mayoritas responden merokok lebih dari 5 tahun (71\%). Tidak terdapat hubungan kebiasaan merokok dengan wrinkles di dahi, mata, nasolabial fold, dan bibir (berturut-turut $\mathrm{p}=0,272 ; \mathrm{p}=0,203 ; \mathrm{p}=0,493$; dan $\mathrm{p}=0,493$; Tabel 2).

\section{Pembahasan}

Berdasar atas Tabel 2 tidak terdapat hubungan antara kebiasaan merokok dan wrinkles di area dahi. Hasil tersebut sesuai dengan penelitian yang dilakukan di Ohio pada tahun 2007-2010 yang diikuti oleh 79 responden didapatkan nilai $\mathrm{p}=0,18$ sehingga disimpulkan tidak didapatkan hubungan antara merokok dan wrinkles di area dahi. Menurut penelitian yang dilaksanakan di Ohio hal tersebut berhubungan dengan salah satu faktor eksternal lain dari penuaan dini, yaitu pergerakan otot yang berulang. Penelitian tersebut menjelaskan tidak terdapat perbedaan frekuensi pergerakan otot dahi pada perokok dengan bukan perokok. ${ }^{6}$

Tidak terdapat hubungan antara kebiasaan

Tabel 1 Kebiasaan Merokok Setiap Hari, Lama Merokok, dan Jenis Rokok

\begin{tabular}{lcc}
\hline Merokok & $\begin{array}{c}\text { Frekuensi } \\
(\mathbf{n}=68)\end{array}$ & $\begin{array}{c}\text { Persentase } \\
\text { (\%) }\end{array}$ \\
\hline Setiap hari & & \\
$\quad$ Ya & 34 & 50 \\
Tidak & 34 & 50 \\
Lama (tahun) & & \\
$\quad 55$ & 10 & 29 \\
$>5$ & 24 & 71 \\
Jenis rokok & & \\
Putih & 15 & 44 \\
Kretek & 6 & 18 \\
Putih dan kretek & 13 & 38 \\
\hline
\end{tabular}

merokok dan wrinkles di mata. Hal ini sesuai dengan penelitian di Ohio yang menunjukkan bahwa tidak terdapat hubungan antara merokok dan wrinkles di seputar mata $(\mathrm{p}=0,78)$. Berbeda dengan penelitian yang lain terdapat karakteristik wrinkles yang menonjol di daerah seputar mata pada orang merokok, yaitu kedalamannya dan keruncingan konturnya. ${ }^{6}$

Tidak terdapat hubungan antara kebiasaan merokok dan wrinkles di area nasolabial fold. Hasil tersebut tidak sesuai dengan penelitian yang dilaksanakan di Ohio yang menunjukkan nilai $\mathrm{p}=0,018$. Perbedaan hasil penelitian ini dengan hasil penelitian di Ohio berhubungan dengan usia subjek, lama merokok, kebiasaan mengonsumsi alkohol, dan tingkat stres subjek pada penelitian berbeda. ${ }^{6}$ Pada penelitian di Ohio subjek yang diteliti berusia lebih dari 40 tahun dengan lama merokok bervariasi, mulai dari 14 tahun sampai 29 tahun. ${ }^{6}$ Berdasar atas penelitian tersebut usia subjek berkaitan dengan lama merokok yang berpengaruh pada timbulnya wrinkles, sedangkan alkohol dan tingkat stres merupakan salah satu faktor eksternal yang dapat memengaruhi penuaan dini pada seseorang. ${ }^{6}$

Tidak terdapat hubungan antara kebiasaan merokok dan wrinkles di bibir, hal ini sesuai dengan penelitian di Ohio yang menunjukkan bahwa tidak ada hubungan antara merokok dan wrinkles di seputar bibir $(\mathrm{p}=0,45)$. Penelitian yang lain menyatakan wrinkles dipengaruhi oleh gerakan wajah yang berulang. ${ }^{6}$

Merokok dalam penelitian ini diteliti berdasar atas jumlah konsumsi rokok per hari dan lama

Tabel 2 Karakteristik Responden berdasar atas Kebiasaan Merokok

\begin{tabular}{lccc}
\hline \multirow{2}{*}{ Wrinkles } & \multicolumn{2}{c}{ Kebiasaan Merokok } & \multirow{2}{*}{$\mathbf{p}$} \\
\cline { 2 - 3 } & Ya & Tidak & \\
\hline Dahi & & & \\
Ya $(\mathrm{n}=18)$ & 11 & 7 & 0,272 \\
Tidak (n=50) & 23 & 27 & \\
Mata & & & \\
Ya (n=12) & 8 & 4 & 0,203 \\
Tidak (n=56) & 26 & 30 & \\
Nasolabial fold & & & \\
Ya (n=2) & 0 & 2 & 0,493 \\
Tidak (n=66) & 34 & 32 & \\
Bibir & & & \\
Ya (n=2) & 2 & 0 & 0,493 \\
Tidak (n=66) & 32 & 34 & \\
\hline
\end{tabular}


waktu merokok dalam hitungan tahun. Hasil yang didapatkan dari kuesioner dan observasi tidak terdapat hubungan yang bermakna antara perilaku merokok dan kejadian penuaan dini.

Faktor intrinsik adalah faktor genetik, bentuk anatomi bervariasi, perubahan hormonal dalam jaringan kutaneus yang ditandai oleh perubahan struktural/elastisitas kulit ${ }^{4}$ berupa fine wrinkles, coarse wrinkles, kulit tipis dan transparan, lemak yang melapisi kulit hilang, serta kulit kering. ${ }^{3}$

Berdasar atas Peraturan Pemerintah RI Nomor 109 Tahun 2012, rokok merupakan salah satu zat adiktif yang bila digunakan mengakibatkan bahaya bagi kesehatan individu dan masyarakat. Rokok adalah hasil olahan tembakau terbungkus termasuk cerutu atau bentuk lain yang dihasilkan dari tanaman Nicotiana tabacum, Nicotiana rustica, dan spesies lainnya, atau sintetisnya yang mengandung nikotin dan tar dengan atau tanpa bahan tambahan. Tar itu bersifat karsinogenik. Nikotin merupakan zat atau bahan senyawa pyrrolidine yang terdapat di dalam Nikotiana tabacum, Nicotiana rustica, dan spesies lainnya, atau sintetisnya yang bersifat adiktif dan dapat mengakibatkan ketergantungan. ${ }^{11}$

Pengaruh rokok itu diawali dengan produksi reactive oxygen species (ROS) $)^{8}$ sehingga terjadi kerusakan pada mitochondrial deoxyribonucleic acid atau mtDNA. Kerusakan mtDNA tersebut akan meningkatkan MMP-1. Matrix metalloproteinase-1 berperan degradasi kolagen/elastin dermis serta molekul ekstraseluler lainnya. Pada perokok diketahui kandungan MMP-1 lebih tinggi daripada bukan perokok sehingga terjadi peningkatan degradasi kolagen dan juga elastin. Akibatnya, perokok memiliki lebih sedikit kolagen dan elastin fiber pada dermis. Keadaan tersebut dapat menyebabkan kekenduran, pengerasan, dan penurunan elastisitas. ${ }^{1,7,8}$

\section{Simpulan}

Merokok tidak berefek pada penuaan dini berupa wrinkles di dahi, seputar mata, nasolabial fold, dan bibir pada sekuriti Unisba usia 20-40 tahun.

\section{Daftar Pustaka}

1. Helfrich YR, Sachs DL, Voorhees JJ. Overview of skin aging and photoaging. Dermatol Nurs. 2008;20(3):177-83.

2. Sveikata K, Balciuniene I, Tutkuviene J. Factor influencing face aging. Literature review. Stomatologija. 2011;13(4):113-6.

3. Sjerobabski-Masnec I, Situm M. Skin aging. Acta Clin Croat. 2010;49(4):515-8.

4. Farage MA, Miller KW, Elsner P, Maibach HI. Intrinsic and extrinsic factors in skin ageing. Int J Cosmet Sci. 2007;30(2):87-95.

5. Piérard GE, Uhoda I, Piérard-Franchimont C. From skin microrelief to wrinkle. An area ripe for investigation. J Cosmet Dermatol. 2003;2(1):21-8.

6. Okada HC, Alleyne B, Varghai K, Kinder K, Guyuron B. Facial changes caused by smoking: a comparison between smoking and nonsmoking identical twins. Plast Reconstr Surg J. 2013;132(5):1085-92.

7. Schroeder P, Schieke SM, Morita A. Premature skin aging by infrared radiation, tobacco smoke and ozone. Dalam: Gilchrest BA, Krutmann J, penyunting. Skin aging. Berlin: Springer-Verlag Berlin Heidelberg; 2006. hlm. 45-53.

8. Drakaki E , Dessinioti C, Antoniou CV. Air pollution and the skin. Front Environ Sci. 2014;2:Article 11.

9. Muizzuddin N, Marenus K, Vallon P, Maes D. Effect of cigarette smoke on skin. J Soc Cosmet Chem. 1997;48(5):235-42.

10. Seitz CM, Strack RW, Wyrick DL. Cigarette smoking and facial wrinkles: a review of the literature. J Smok Cessat. 2012;7(1):18-24.

11. Peraturan Pemerintah Republik Indonesia Nomor 19 Tahun 2003 tentang Pengamanan Rokok Bagi Kesehatan. 